\title{
Has fractionation in head and neck cancer radiotherapy reached a summit or is there still room for novel therapeutic strategies?
}

\author{
Bogusław Maciejewski1,2, Leszek Miszczyk², Krzysztof Składowski² \\ ${ }^{1}$ Div. Research Programmes \\ ${ }^{2}$ Radiotherapy and Chemotherapy Clinic, M. Sklodowska-Curie National Research Institute of Oncology, Gliwice Branch, Poland
}

\begin{abstract}
The aim of this paper is to answer to the question whether various dose fractionation regimens are highly effective up to the summit of normal tissue tolerance. Data from 45 trials on altered fractionation, radio-response of the HPV $(+)$ oropharyngeal cancer (OPC) and concurrent chemoradiation (11533 data) have been selected from the published papers and re-analysed. Altered fractionation regimens showed an average therapeutic gain (TG) of local tumour control (LTC) of about 2.7\% per each 1 izoGy 2.0 above 65 Gy. For HPV(+) OPC, TG increased by 3-3.5\%/1 izoGy ${ }_{20}$. Concurrent chemoradiation for locally advanced H\&N cancer produced about 60\% LTC using 65 Gy (about 20\% more than altered RT). Despite randomization, data sets in the trials remain clinically and biologically heterogeneous. It is not possible to separate the TG rate as the result of change in dose per fraction from that caused by changing the overall treatment time. This is major weakness of the trials. Moreover, the results are presented as an average value of the LTC or survival. The overstepped tolerance summit is very rarely precisely presented. It likely seems that the tolerance summit is not a single value and is only partly related to dose fractionation intensity, it mainly depends on radiosensitivity and the irradiation volume of normal tissue(s) and their potential repair capacity, and an activation of immunological defense. Finally, it is difficult to accept average trial' results as evidence based guidelines for personalized radiotherapy for individual patients; what is more the individual tolerance summit is not universal and well quantified.
\end{abstract}

Key words: radiotherapy and chemoradiation regimens, weaknesses and benefits, tolerance summits

\section{Introduction}

In the 1930s, Coutard proposed to divide a total dose into small daily doses (fractions) instead of a single-dose or a few large fractions. This would spare normal tissues surrounding the tumour, and therefore decrease the risk of severe acute and late complications. This method was called "simple fractionation", i.e. the delivery of small fraction sizes at relatively high dose-rates. Coutard's regimen gained wide interest across many centers, and it was brought to the US by Gilbert
Fletcher and established as a curative standard radiotherapy using 60 Gy in 30 fractions, in 42 days, up to 70 Gy in 35 fractions, in 49 days. It was eventually defined as "conventional fractionation" and has been continuously applied through consecutive decades in almost all radiotherapy centers. The only exception was 51 Gy in 17 fractions in 22 days used by Paterson in Manchester during World War Il; this was curative therapy for early stage head and neck cancer, and it is still used in Manchester.

\section{How to cite:}

Maciejewski B, Miszczyk L, Składowski K. Has fractionation in head and neck cancer radiotherapy reached a summit or is there still room for novel therapeutic strategies? NOWOTWORY J Oncol 2021; 71: 94-102.

This article is available in open access under Creative Common Attribution-Non-Commercial-No Derivatives 4.0 International (CC BY-NC-ND 4.0) license, allowing to download articles and share them with others as long as they credit the authors and the publisher, but without permission to change them in any way or use them commercially 
Until the late 1970s conventional radiotherapy was commonly applied, and serious efforts were done to determine which conventional schedule could maximize the therapeutic gain $[1,2]$. However, over the past ten decades, the terms "tolerance dose and patient's tolerance" have not been precisely defined and counted. Does tolerance concern patient's specific organ, tissue, or its part, still remains unclear, and it is unlikely to design a dose reaching the summit of undefined target. Nevertheless, after many years of clinical experience, conventional fractionation has met with growing disappointment, since it resulted in average 30-40\% locoregional control, mainly because the majority of patients had locally advanced stages of cancer. However, a new, and promising wind was blowing from radiobiology.

Many experimental and clinical studies have shown that the time factor - OTT (the shorter the better) and the size of dose per fraction (di) have a major impact on radiotherapy treatment outcomes.

A new term "altered fractionation" has appeared on the market. Many different "new" fractionation regimens were designed and tested clinically. In principle, they represent one of the three following categories: accelerated (with shortened OTT), hyperfractionated (dose per fraction lower than 2.0 Gy, usually given twice or trice-a-day) and hybrid-accelerated hyperfractionated with both a low fraction size and short OTT $[3,4]$. Between the 1990s and 2015 more than 50 clinical studies (mainly trials) were carried out that recruited more than 50000 patients. However, two meta-analyses [5, 6] selected only 15 trials (30\%) and have shown rather disappointing results with an average 4-6\% local control benefit (TG). Glatstein [7-9] convincingly questioned the reliability of statistics and results of meta-analyses, emphasizing their doubts and uncertainties. He pointed out that the statistical significance in clinical trials does not necessarily mean clinical importance. The same uncertainties apply to the meta-analyses of combined chemoradiation [10-15].

Among others, doubts and low confidence are caused by the fact, that oropharyngeal cancers were the most frequent tumour site of the recruited cases. Radiosensitivity and local tumour control (LTC) of the HPV(+) oropharyngeal cancers (OPC) are higher than for other sites of H\&N tumours and have been well documented $[16,17]$. Therefore they could likely affect the final results of clinical trials and meta-analyses as well, but they were not quantified at the time the trials were carried out.

Both clinical trials and meta-analyses data are highly heterogeneous regarding clinical (location, staging), biological (sensitivity) and dose fractionation parameters. It likely makes the accuracy and reliability of the results highly uncertain; the real benefit of altered radiotherapy and combined chemoradiation remains partially negligent. For that reason, reanalyses of the available data sets of these two radiotherapy issues is the aim of the present study.

\section{Material and methods}

The present study includes only those trial' data sets which precisely document clinical factors (localization and staging), fractionation parameters (total dose - TD, dose per fraction - di, overall treatment time - OTT), and the rates of at least 3 year locoregional control, that are:

- 22 studies (trials) on altered fractionation (6027 head and neck cancer patients)

- 8 studies (trials) evaluating the impact of the HPV status of the OPC on the RT outcome (2195 patients),

- 15 studies (trials) on concurrent chemoradiation (3311 patients)

Together this gives 11533 data. In the majority of cases they are locally advanced head and neck cancer cases in stage III-IV, with a pronounced number of OPC tumours. The rate of T1-2N0-1 tumours was usually very small. Different regimens of accelerated $(A)$, hyperfractionated $(H)$, a hybrid $(H-A)$ dose fractionation were used. The analysed data sets characterize wide differences in clinical factors (i.e. tumour localization, staging). Similar variety concerns fractionation parameters of RT (TD, di, OTT). Therefore, in the present study they are unified by the following normalized total dose (NTD) formula:

$\mathrm{NTD}=\mathrm{TD}[(\mathrm{di}+\mathrm{a} / \beta) /(2.0+\mathrm{a} / \beta)-0.6 \mathrm{~Gy} / \mathrm{d} \cdot(\mathrm{OTT}-42$ days $)]$

in which $\alpha / \beta=10 \mathrm{~Gy}$ is used, and NTD represent an izoeffective biological total dose $\left(\right.$ izoGy $_{2.0}$ ), if given in 2.0 Gy fractions, in the OTT of 42 days.

The range of $60 \mathrm{~Gy}$ in 42 days ( $\mathrm{TD}=60 \mathrm{izoGy}_{2.0}$ ) to $70 \mathrm{~Gy}$ in 50 days (NTD $=65.2 \mathrm{izoGy}_{2.0}$ ) is arbitrarily chosen as a standard conventional RT, which usually resulted in $30-40 \%$ of 3 -year locoregional control (LRC).

At least 3-year therapeutic gain achieved by altered fractionation $(A, H, H-A)$ was counted for each of the selected studies as follows:

$$
\mathrm{TG}_{\mathrm{LRC}}=\% \mathrm{LRC}_{\text {altered }}-\% \mathrm{LRC}_{\text {control }}
$$

\section{Results}

\section{Altered fractionation}

The therapeutic gain (TG) achieved in the altered fractionation trials is presented in table I in details. In 10 of 22 studies (45\%), the local tumour control (LTC) rate of conventional fractionation (control arm) was within the arbitrarily accepted rate of $30-40 \%$, however in 7 studies (32\%) the LTC was higher than $40 \%$, whereas in three trials (14\%) it was below 30\%. It already reflects a huge clinical and biological heterogeneity of the recruited patients. Only in 5 trials (23\%), the TG of altered regimens higher than 10\%. An unexpectedly high TG of $42 \%$ was noted in the CAIR, which included fairly homogenous tumours T1-4N0-1. However, this result was criticized by some authors, who suggested careful conclusion, since the relatively small number of patients recruited to the prematurely closed trial 
Table I. Characteristics and local tumour control. Therapeutic gain of selected studies (trials) on altered fractionated irradiation

\begin{tabular}{|c|c|c|c|c|c|c|c|c|}
\hline \multirow{2}{*}{\multicolumn{2}{|c|}{ Fractionation }} & \multirow[b]{2}{*}{$\begin{array}{l}\text { No. } \\
\text { patients }\end{array}$} & \multicolumn{3}{|c|}{ Schedule } & \multirow[b]{2}{*}{$\begin{array}{c}\text { NTD } \\
\text { izoGy }_{2.0}\end{array}$} & \multirow[b]{2}{*}{ Therapeutic gain (LTC\%) 3 years } & \multirow[b]{2}{*}{ Author(s), trial } \\
\hline & & & $\begin{array}{c}\text { TD } \\
\text { in Gy }\end{array}$ & $\begin{array}{c}\text { di } \\
\text { in Gy }\end{array}$ & $\begin{array}{c}\text { OTT } \\
\text { in days }\end{array}$ & & & \\
\hline \multirow{2}{*}{\multicolumn{2}{|c|}{$\begin{array}{l}\text { standard } \\
\text { conventional }\end{array}$}} & & 60 & 2.0 & 42 & 60 & \multirow{2}{*}{ average: $35-45 \%$} & \multirow[b]{3}{*}{ CHART, Saunders $[3,4]$} \\
\hline & & & 70 & 2.0 & 49 & 65.8 & & \\
\hline 1. & $\mathrm{H}-\mathrm{A}$ & 918 & 54 & 1.5 (tid) & 14 & 68.6 & $\begin{array}{c}+5 \% \text { ( } 49 \% \text { vs. } 42 \%) \\
0 \% \text { after } 10 \text { yrs. }\end{array}$ & \\
\hline 2. & $\mathrm{H}-\mathrm{A}$ & 70 & 46 & 1.4 (tid) & 14 & 60.5 & $+5 \%(54 \%$ vs. $49 \%)$ & Awward $[3,4]$ \\
\hline 3. & $\mathrm{H}-\mathrm{A}$ & 429 & 54.4 & 1.6 (bid) & 24 & 63.4 & no diff. & RTOG $9104[3,4]$ \\
\hline 4. & $\mathrm{H}-\mathrm{A}$ & 161 & 54 & 2.0 (tid) & 12 & 72.0 & $+9 \%(44 \%$ vs. $35 \%)$ & Olmi $[3,4]$ \\
\hline 5. & $\mathrm{H}-\mathrm{A}$ & 336 & 58 & 1.45 (bid) & 28 & 63.7 & $+8 \%(45 \%$ vs. $37 \%)$ & PMH, Cummings $[3,4]$ \\
\hline 6. & $\mathrm{H}-\mathrm{A}$ & 350 & 59.4 & 1.8 (bid) & 25 & 68.6 & $+5 \%(48 \%$ vs. $43 \%)$ & Poulsen $[3,4]$ \\
\hline 7. & A & 791 & 66 & 2.0 (sid) & 36 & 69.6 & $+9 \%(66 \%$ vs. $57 \%)$ & DAHANCA, Overgaard $[3,4]$ \\
\hline 8. & A & 82 & 66 & 2.0 (bid) & 25 & 70.2 & $+4 \%(62 \%$ vs. $58 \%)$ & Jackson $[3,4]$ \\
\hline 9. & A & 268 & 63 & 2.0 (bid) & 24 & 73.8 & $+12 \%$ (46\% vs. $34 \%)$ & Bourhis $[3,4]$ \\
\hline 10. & A & 100 & 70 & $2.0(7 \mathrm{~d} / w k)$ & 35 & 74.2 & $+42 \%(75 \%$ vs. $33 \%)$ & $\begin{array}{l}\text { CAIR (CLE) } \\
\text { Składowski }[3,4]\end{array}$ \\
\hline 11. & $\mathrm{H}-\mathrm{A}$ & 500 & 72 & 1.6 (tid) & 35 & 73.8 & $+7 \%$ (59\% vs. $46 \%)$ & $\begin{array}{l}\text { EORTC 22851, } \\
\text { Horiot }[3,4]\end{array}$ \\
\hline 12. & $\mathrm{H}$ & 178 & 72 & $0.9 \times 8 / d$ & 42 & 72 & no gain (40\%) & Nguyen $[3,4]$ \\
\hline 13. & $\mathrm{H}$ & 165 & $60-75$ & 1.2 (bid) & $35-45$ & $61-67.9$ & no gain (40\%) & Moez $[3,4]$ \\
\hline \multirow{2}{*}{14.} & \multirow{2}{*}{$\mathrm{H}$} & \multirow{2}{*}{447} & $\begin{array}{l}67.2 \\
72.0\end{array}$ & $\begin{array}{l}1.2 \text { (bid) } \\
1.2 \text { (bid) }\end{array}$ & $\begin{array}{l}38 \\
42\end{array}$ & $\begin{array}{c}65 \\
67.2\end{array}$ & \multirow{2}{*}{$\begin{array}{l}+19 \%(44 \% \text { vs. } 25 \%) \\
\text { no gain ( } 45 \% \text { vs. } 43 \%)\end{array}$} & \multirow{2}{*}{$\begin{array}{l}\text { TRTOG } 8313,9003 \\
\text { Cox, Fu }[3,4]\end{array}$} \\
\hline & & & $\begin{array}{l}76.8 \\
81.6\end{array}$ & $\begin{array}{l}1.2 \text { (bid) } \\
1.2 \text { (bid) }\end{array}$ & $\begin{array}{l}51 \\
54\end{array}$ & $\begin{array}{l}69.8 \\
69.9\end{array}$ & & \\
\hline 15. & $\mathrm{H}$ & 356 & 80.5 & 1.15 (bid) & 49 & 70.5 & $+18 \%$ (56\% vs. $58 \%)$ & $\begin{array}{l}\text { EORTC } 22791 \\
\text { Horiot }[3,4]\end{array}$ \\
\hline 16. & $\mathrm{H}-\mathrm{A}$ & 79 & 72 & $\begin{array}{c}1.8 \text { (bid) } \\
\text { (boost last } \\
2 \text { wks) }\end{array}$ & 42 & 70.8 & $+13 \%$ (79\% vs. 66\%) & RTOG 85-88, Ang $[3,4]$ \\
\hline 17. & A & 350 & 59.4 & 1.8 (bid) & 24 & 69.2 & $+3 \%(54 \%$ vs. $51 \%)$ & TROG 910, Denham $[3,4]$ \\
\hline 18. & $\mathrm{H}-\mathrm{A}$ & 145 & 66 & 1.1 (bid) & 45 & 62.9 & $+10 \%(74 \%$ vs. $69 \%)$ & Pinto $[3,4]$ \\
\hline 19. & A & 94 & 60 & 2.0 (bid) & 35 & 64.2 & $+1 \%(30 \%$ vs. $29 \%)$ & Marcial $[3,4]$ \\
\hline 20. & $\mathrm{H}-\mathrm{A}$ & 105 & 58.5 & 1.5 (tid) & 18 & 70.5 & $+10 \%$ (44\% vs. $34 \%)$ & Belau $[3,4]$ \\
\hline 21. & $\mathrm{H}-\mathrm{A}$ & 91 & 79.2 & 1.2 (bid) & 45 & 72.1 & $+15 \%$ (43\% vs. $28 \%)$ & Datta $[3,4]$ \\
\hline 22. & $\mathrm{H}-\mathrm{A}$ & 12 & 76 & $\begin{array}{l}1.2-1.6 \\
\text { (bid) }\end{array}$ & 35 & 77 & no gain (CLE!) & HARDE, Harari $[3,4]$ \\
\hline
\end{tabular}

RT: A - accelerated; $\mathrm{H}$ - hyperfractionated; $\mathrm{H}$-A - accelerated hyperfractionation; sid - once-a-day; bid - twice-a-day; tid - thrice-a-day; TG - \% gain in LTC compared with standard arm; NTD - normalized total dose if given in $2.0 \mathrm{~Gy}$ fractions = TDi (di = $10 \mathrm{~Gy}) /(2.0 \mathrm{~Gy}+10 \mathrm{~Gy})$ for a/b = $10 \mathrm{~Gy}$; CLE - consequential late effects, severe acute reactions

raises well-grounded uncertainties. In the other 5 trials (23\%) zero TG benefit of altered regimens was noted. For example, in the CHART the average 5-year TG of 5\% dropped down to zero after 10-years follow-up [10].

An altered fractionation TG of $10 \%$ or higher was found in the trials which in the tested arm used a dose per fraction much lower than $2.0 \mathrm{~Gy}$, given twice- or trice-a-day (pure hyperfractionation or accelerated hyperfractionation). Bourhis et al. [5] and Lucas et al. [6] reported an average 6.4\% benefit of LTC (at 5-years; $p<0.0001$ ) in favour of altered regimens. Such average value does not reflect the real benefit of some individual studies. Figure 1 shows that LTC at the level of $40 \%$ raises by about $20 \%$ with increasing NTD by 7.5 izoGy $_{2.0}$ (from 66.5 izoGy $_{2.0}$ to 73 izoGy $_{2.0}$ ), which gives an average increase in the TG of $2.7 \%$ by each 1 izoGy 2.0 above 66.5 izoGy $_{2.0}$. It has to be pointed out that this single value represents highly heterogeneous sets of patients recruited to the trials (from T2NO to T4N3), and therefore it is likely to be biased. For carefully 


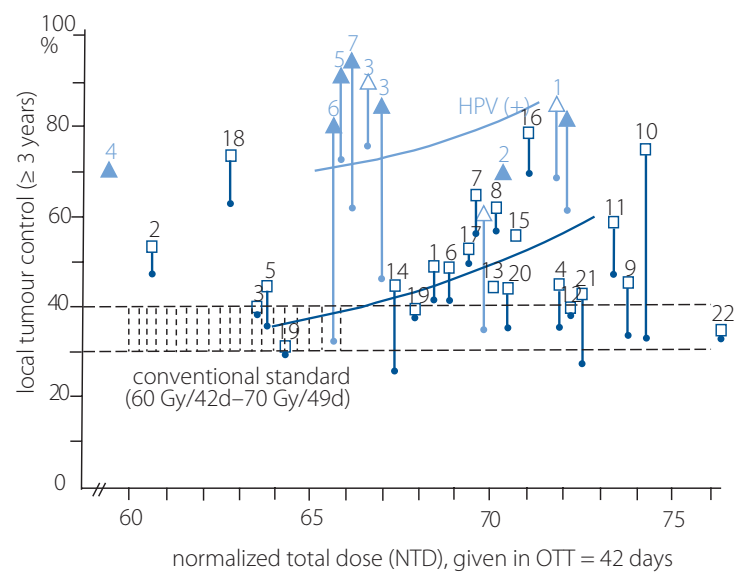

Figure 1. Local tumour control - NTD relationship for altered fractionation series compared with HPV(+) oropharyngeal cancer ( $\triangle$ - LTC - OC)

selected data sets with a single tumour site and homogeneous stage, the LTC benefit in favour and of an altered regimen might

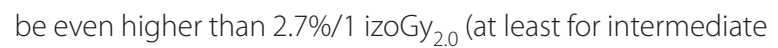
local stages of disease).

\section{$H P V(+)$ status of oropharyngeal cancer (OPC)}

Intensive interest has focused on oropharyngeal cancer (OPC), because of the beneficial impact of HPV(+) status on radiotherapy outcomes. Patients with HPV(+) OPC have much better prognosis, higher locoregional control and overall survival than those with HPV(-) or other head and neck tumours. Nowadays, HPV(+) OPCs are widely recognized as a distinct head and neck cancer entity.

Although numerous studies have been focused on that topic, except the strengths, some results are uncertain. For that reason, the present study includes only detailed and pertinent data to analyse the importance of the HPV status of the OPCs relevant to clinical practice. The results of 8 studies (trials) with almost 3000 patients are presented in details in table II. The range of the NTDs is similar to that used in the "altered" series, which should not surprise since some of them were also a part of the "altered"trials. Moreover, with the exception of the RTOG 0129 trial (tab. II, No. 1), the RT was combined with chemotherapy (inductions, adjuvant or concurrent). Usually, the major end-point was overall survival (OS), but in 4 studies, the LTC was also reported. At the first glance, the LTC therapeutic gain for the HPV(+) OPCs was much higher than that achieved in the "altered" studies, which was also accompanied by significant increase of the OS. Figure 1 illustrates this tendency within the NTD of 66.5-73 izoGy $_{2.0}$ (the same as for "altered" data).

The LTC rates were on average $20-30 \%$ higher than those representing the "altered" data sets, which gives an average increase of the TG of about 3-3.5\% by each 1 izoGy $_{2.0^{\prime}}$ above $66.5 \mathrm{izoGy}_{2.0}$. Even though this value is not far away from the "altered"TG/1 izoGy 2.0 , but the HPV(+) LTC curve is on a higher level than that representing the "altered" results. It likely suggests higher sensitivity and radioresponsivenes of the HPV(+) OPCs (25-30\% higher LTC) than that for other H\&N tumours. The ECOG 1308 trial (tab. II, No. 4) showed that induction chemotherapy with paclitaxel and carboplatin for HPV(+) OPCs combined with a total dose lowered to 54 Gy in 37 days gave very high LRC (83\%) and OS (95\%). Therefore, for low risk HPV(+) OPC patients it may likely advocate for de-escalation of radiotherapy dose if combined with chemotherapy [12-14].

\section{Chemoradiation}

For the last 2 decades, chemotherapy combined with radiotherapy (mainly concurrent chemoradiation) with locally advanced H\&N cancers has been an object of extensive cli-

Table II. Radiotherapy alone or chemotherapy for PV(+)/HPV(-) oropharyngeal cancer

\begin{tabular}{|c|c|c|c|c|c|c|c|c|}
\hline \multirow[t]{2}{*}{ L. $p$. } & \multirow[t]{2}{*}{ Therapy regimen } & \multirow{2}{*}{$\begin{array}{c}\text { No. } \\
\text { patients }\end{array}$} & \multicolumn{2}{|c|}{ Schedule } & \multirow{2}{*}{$\begin{array}{l}\text { NTD } \\
\text { in } \\
\text { izoGy }_{2.0}\end{array}$} & \multicolumn{2}{|c|}{ Therapeutic gain } & \multirow[t]{2}{*}{ Author(s) } \\
\hline & & & $\begin{array}{l}\text { TD } \\
\text { in Gy }\end{array}$ & $\begin{array}{l}\text { OTT in } \\
\text { days }\end{array}$ & & $\begin{array}{c}\text { in LRC } \\
\mathrm{HPV}+/ \mathrm{HPV}-\end{array}$ & $\begin{array}{c}\text { in OS } \\
\mathrm{HPV}+/ \mathrm{HPV}-\end{array}$ & \\
\hline 1. & RTOG 0129 & 720 & 72 & 42 & 72 & $+21 \%(86 \%$ vs. $65 \%)$ & $+25 \%(82 \%$ vs. $57 \%)$ & Ang $[11,12,13]$ \\
\hline 2. & $\begin{array}{l}\text { DAHANCA 6-7 with } \\
\text { nimorazole }(\mathrm{Nm})\end{array}$ & 331 & 68 & 40 & $\sim 70 \mathrm{Nm}(+)$ & $+26 \%$ (61\% vs. $35 \%)$ & $\begin{array}{l}+30 \%(70 \% \text { vs. } 40 \%) \\
+21 \%(63 \% \text { vs. } 42 \%)\end{array}$ & Lassen $[11,12,13]$ \\
\hline 3. & $\begin{array}{l}\text { PMH (2011-2013) } \\
\pm \text { cispl (concur.) }\end{array}$ & 449 & 70 & 49 & $\begin{array}{c}66.4 \\
+ \text { cispl } \\
\text { no cispl }\end{array}$ & $\begin{array}{l}+17 \%(93 \% \text { vs. } 76 \%) \\
+14 \%(90 \% \text { vs. } 76 \%)\end{array}$ & $\begin{array}{l}+45 \%(89 \% \text { vs. } 44 \%) \\
+26 \%(70 \% \text { vs. } 44 \%)\end{array}$ & $\begin{array}{l}\text { O'Sullivan [11, } \\
12,13]\end{array}$ \\
\hline 4. & $\begin{array}{l}\text { ECOG } 1308 \\
\text { induc palitaxel + carboplatin. }\end{array}$ & 90 & 54 & 37 & 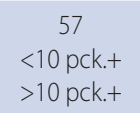 & not reported & $\begin{array}{l}95 \% \\
76 \%\end{array}$ & Marur $[11,12,13]$ \\
\hline 5. & TROG 02.02. tirapazamin/cispl & 185 & 70 & 49 & 65.8 & not reported & $+17 \%$ (91\% vs. $74 \%)$ & Risch $[11,12,13]$ \\
\hline 6. & $\begin{array}{l}\text { TAX } 324 \text { include. CHT } \\
\text { docetaxel, cispl, 5-Fu }\end{array}$ & 264 & 70 & 49 & 65.8 & not reported & $+49 \%(80 \%$ vs. $35 \%)$ & $\begin{array}{c}\text { Posner [11, 12, } \\
13]\end{array}$ \\
\hline 7. & $\begin{array}{l}\text { ECOG } 2399 \\
\text { carbopl, paclitax + adj. } \\
\text { paclitaxel. }\end{array}$ & 111 & 70 & 49 & 65.8 & not reported & $+33 \%(95 \%$ vs. 62\%) & Fakhry $[11,12,13]$ \\
\hline
\end{tabular}

NTD calculated as in app. 1; di - in all studies was $2.0 \mathrm{~Gy}$ 


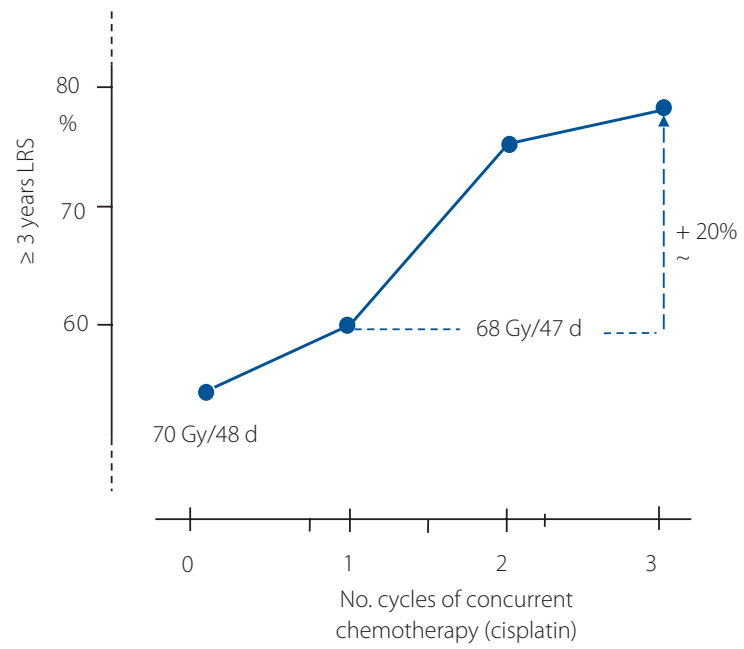

Figure 2. Local tumour control - NTD relationship for differed radiotherapy versus chemoradiation ( $T X$ - taxans)

nical studies (more than 70 trials). Some of them, including meta-analyses [15-17] have reported the therapeutic benefit of combined chemoradiation, whereas others $[18,19]$ have concluded that such benefit remains as yet uncertain.
Table III presents 15 carefully selected studies on chemotherapy combines with radiotherapy (mainly hyperfractionation). The three-year LTC therapeutic gain ranged from $8 \%$ to more than 20\%, and generally is higher than that achieved by "altered" regimens. However, contrary to "altered" results, 20\% TG was achieved by CH-RT using NTD 2.0 lowered from 70 izoGy $_{2.0}$ to 65 izoGy $_{2.0}$. Thus, about $60 \% 3$-year LTC of locally advanced $\mathrm{H} \& \mathrm{~N}$ cancers can be expected using hyperfractionation combined with concurrent chemotherapy. An interesting study was carried out by Składowski using concurrent $\mathrm{CH}$ -RT (cisplatin) for cancer of the oro-hypopharynx and larynx (T2-4N0-1). He has noted about 20\% higher LTC when 2 cycles of concurrent $\mathrm{CHT}$ was used instead of one cycle. The use of 3 cycles instead of 2 although producing further increases in the LTC, was not particularly substantial (fig. 3).

\section{Discussion}

\section{Altered radiotherapy vs. concurrent chemoradiation}

A major question in radiotherapy, which still waits to be answered, is what does the word summit actually mean? Is it

Table III. Dose fractionation and LTC therapeutic gain of selected chemoradiation studies (trials)

\begin{tabular}{|c|c|c|c|c|c|c|c|c|c|}
\hline L. p. & Therapy regimen & $\begin{array}{c}\text { No. } \\
\text { patients }\end{array}$ & $\begin{array}{l}\text { TD } \\
\text { in Gy }\end{array}$ & $\begin{array}{l}\text { di } \\
\text { in Gy }\end{array}$ & $\begin{array}{c}\text { OTT } \\
\text { in days }\end{array}$ & $\begin{array}{l}\text { NTD } \\
\text { izoGy }_{2.0}\end{array}$ & \multicolumn{2}{|c|}{$\begin{array}{c}\text { Therapeutic gain (LTC\%) } \\
3 \text { years }\end{array}$} & $\begin{array}{l}\text { Author(s), } \\
\text { trial }\end{array}$ \\
\hline 1. & V-CHART with mitomycin on day 5 & 239 & 55.3 & 1.65 (bid) & 17 & 68.6 & $+17 \%$ & (48\% vs. $31 \%)$ & Dobrovsky $[3,4]$ \\
\hline 2. & German trial with carbopl + 5-Fu & 240 & 69.9 & $1.8+1.5$ (bid) & 38 & 71.7 & $+6 \%$ & (51\% vs. $45 \%)$ & Staar $[3,4]$ \\
\hline 3. & MGH trial with cispl + 5-Fu & 416 & 76 & di $\times 6 / w k$ & 42 & 76 & $+11 \%$ & ( $27 \%$ vs. $16 \%)$ & Wang $[3,4]$ \\
\hline 4. & $\mathrm{H}+$ cispl daily (low dose) & 218 & 77 & 1.1 (bid) & 48 & 68.7 & $+14 \%$ & (50\% vs. $36 \%)$ & Jeremic $[3,4]$ \\
\hline 5. & $H+$ cispl +5 -Fu for $5 d$ & 136 & 75 & CB (bid) & 42 & 73 & $+5 \%$ & (332\% vs. $27 \%)$ & Corvo $[3,4]$ \\
\hline 6. & $H+$ cispl + 5-Fu, wk. 1,6 & 122 & 70 & 1.25 (bid) & 46 & 66.6 & $+26 \%$ & (70\% vs. $44 \%)$ & Denham $[3,4]$ \\
\hline 7. & $\mathrm{H}+$ cispl $+5-\mathrm{Fu}+$ leucovorin & 270 & 70.2 & 1.8 (bid) & 42 & 69 & $+19 \%$ & (36\% vs. $17 \%)$ & Byhardt $[3,4]$ \\
\hline 8. & $H+$ cispl daily & 130 & 77 & 1.1 (bid) & 48 & 68.7 & $+14 \%$ & (50\% vs. $36 \%)$ & Denham $[3,4]$ \\
\hline 9. & $\mathrm{H}+5-\mathrm{Fu}+$ mitomycin & 384 & 70.6 & $2.0+1.4$ & 42 & 69.2 & $+13 \%$ & $(50 \%$ vs. $35 \%)$ & Budach $[3,4]$ \\
\hline 10. & $\begin{array}{l}\text { std. + carbopl. + 5-Fu } \\
\text { French trial 94-01 }\end{array}$ & 226 & 70 & 2.0 & 48 & 66.4 & $+23 \%$ & (48\% vs. $25 \%)$ & Denis $[3,4]$ \\
\hline 11. & stand + cispl + 5-Fu & 100 & 70 & 2.0 & 48 & 66.4 & $+20 \%$ & (55\% vs. $35 \%)$ & Adelstein $[3,4]$ \\
\hline 12. & stand + MMC & 195 & 68 & 2.0 & 46 & 65.6 & $+22 \%$ & (76\% vs. $54 \%)$ & Haffty $[3,4]$ \\
\hline 13. & $\begin{array}{l}\text { stand }+ \text { A. induction } 5-\mathrm{Fu}+\text { cispl } \\
\text { B. concurrent cispl } \\
\text { C. RT alone }\end{array}$ & 547 & $\begin{array}{l}70 \\
70 \\
70\end{array}$ & $\begin{array}{l}2.0 \\
2.0 \\
2.0\end{array}$ & 48 & $\begin{array}{l}66.4 \\
66.4 \\
66.4\end{array}$ & $\begin{array}{l}+5 \% \\
+22 \%\end{array}$ & $\begin{array}{c}(61 \% \text { vs. } 56 \%) \\
(78 \% \text { vs. } 56 \%) \\
56 \%\end{array}$ & $\begin{array}{l}\text { R91-11 } \\
\text { Forestier }[3,4]\end{array}$ \\
\hline 14. & $\begin{array}{l}\mathrm{H}-\mathrm{A}+\text { paclitaxel } 5-\mathrm{Fu}+ \\
\text { hydroxyurea }\end{array}$ & 55 & 75 & 1.5 (bid) & 35 & 76 & $+20 \%$ & (40\% vs. $20 \%)$ & $\begin{array}{l}\text { phase II, } \\
\text { Vokes }[3,4]\end{array}$ \\
\hline 15. & $\mathrm{H}-\mathrm{A}+$ paclitaxel + carbopl & 33 & 66.6 & 1.8 (bid) & 35 & 69.7 & $60 \%$ & & $\begin{array}{l}\text { phase II, } \\
\text { Chongule [3,4] } \\
\text { Składowski } \\
\text { [personal, 28] }\end{array}$ \\
\hline 16. & $\begin{array}{r}\text { stand }+ \text { concurrent cispl } \\
2 \text { cycles } \\
3 \text { cycles }\end{array}$ & 114 & 68 & 2.0 & 47 & 68 & $\begin{array}{l}+20 \% \\
+25 \%\end{array}$ & $\begin{array}{l}(75 \% \text { vs. } 55 \%) \\
(\sim 80 \% \text { vs. } 75 \%)\end{array}$ & \\
\hline
\end{tabular}

NTD calculated as in app. 1 


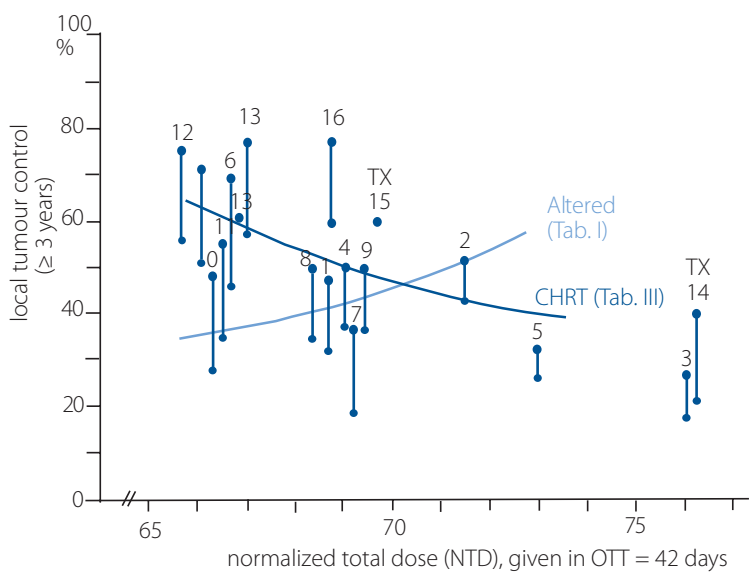

Figure 3. Improvement of 3-yr. LTC depending on the number of concurrent $\mathrm{CH}$ used during the course of RT

a real or merely theoretical term? What is the optimal limit for dose escalation? Theoretically, an escalation of the fractionated dose might be unlimited to achieve permanent patient'cure. However, the tolerance (repairable injury) of normal tissues surrounding the tumour was recognized relatively early as a summit for fractionated dosing.

In the head and neck region, the severity and area of early mucosal reactions are the major factors which define the limit which a dose can be escalated to, but it differs on an individual basis. The sensitivity of acute reactions can be quantified during the course of therapy, whereas the risk of late effect (complication) can only be predicted [20].

Therapeutic gain considered as an increase in the LTC is a function of the steepness of the dose-response curves for the tumour and acute or late injury specific normal tissues [2]. The highest TG can be expected if the reference (control) TCP is defined by the central or steeper part of the dose-response curve (i.e. about 40-50\%) which usually refers to the response of locally advanced H\&N cancers. It likely suggests that conventional dose fractionation seems to be not powerful enough to produce high TCP, and "altered" fractionation could be a promising alternative. For over 20 years, the results of about 50 "altered" trials and meta-analyses [5, 6] gave a disappointing average TG of $6.4 \%$, much lower than initially expected [5]. Present results (tab. I) show that such average disappointment is not necessarily well-grounded because in some trials (tab. I, No. 9, 14, 15, 21) the TG was higher than 10\%.

Glatstein $[7,8]$ convincingly criticized the statistics of the trials' and meta-analyses results and indicated the various biases and pitfalls involved. Interpreting the 3-5-year LTC and OS curves he used the term "the tyranny of the median value". In general, there is the tempting tendency to limit the LTC or OS curves to a single value (3- or 5-year), which is a means value and the remaining part of the LTC or OS curves (the noise of individual data points prior, around, or after the mean value-point on the curve) is usually ignored.
Apart from these doubts, there are two major weaknesses and faults of "altered" trials and meta-analyses. Although the obligatory rules of randomization and stratification were strictly complied, only 19 of the 50 trials were selected for meta-analyses, because of various violations in the remaining studies (70\%!). Moreover, patients in both arms of the selected trials still represent high heterogeneity regarding clinical and biological factors (various tumour sites and wide range of stages from T2N0 to T4N3). Although an enormous amount of clinical data was gathered, it is still impossible to separate the clinical effect of changes in dose per fraction from that being the result of change in the OTT.

In the present study, use of the Normalized Total Dose (NTD) allows to express different values of the TD, di and OTT as a single parameter. Figure 1 shows that increase NTD above 65 izoGy $_{2.0}$ resulted in an increase of the TG by $2.7 \%$, by each extra 1 izoGy $_{2.0}$. It gives the TG higher than the mean value of $6.4 \%$ reported by Bourhis et al. [5]. Nowadays, the preliminary hypothesis that clinical testing an efficacy of various fractionation regimens could miraculously provide a single "altered Holy Grail regimen"for all various advanced head and neck cancers, seems somewhat naive. On the other hand, for some carefully selected and homogeneous subgroups of tumours, the TG could be higher than the estimated average mean value. This suggestion is confirmed by the DAHANCA trial. For selected well differentiated squamous cell cancers, the TG increased from $9 \%$ to about $20 \%$.

Finally, it seems that altered fractionation regimens did not reach a summit, although in a few studies it even over stepped. Nguyen et al. [3, 4] designed an interesting regimen using 8 very small fractions of 0.9 Gy per day, but with only 2-hours interfraction intervals. Despite the rather high LTC in more than 50\% patients early severe and extensive necrosis occurred (consequential late effect - CLE) which led to a patient' death. A similar overstepped summit was observed in the early period of the CAIR (tab. I, No. 10) and HARDE (tab. I, No. 22) trials, it was a consequence of a too high accumulated dose per week in these purely accelerated regimens. Finally, despite a lot of effort being put into testing various altered fractionation regimens, the hyperfractionated concomitant boost regimen remains that which is used in clinical practice.

The majority of patients recruited to "altered" trials had oropharyngeal cancer (OPC). It was well documented that $\mathrm{HPV}(+) \mathrm{OPC}$ are more radiosensitive with their LTC and OS being much higher than those for HPV(-) tumours. Hyperfractionated RT combined with chemotherapy resulted in significantly higher TG for the HPV(+) tumours compared with HPV(-) (tab. II), ranged from 14\% to over 25\% (the LTC was in the range of $61-93 \%)$. Similarly, the OS gain was also higher (24-45\%), when compared with HPV(-) cases. LTC benefit of the HPV(+) OPC patients was significantly higher (70-80\%) then that achieved by altered fractionation (40-60\%). Therefore, it has been suggested that the high LTC benefit of the 
HPV(+) OPC patients can likely be achieved by using a total dose de-escalated by 10-15\% (tab. II, No. 4), which is illustrated in figure 1. Since the OPC patient quite often participated in "altered"trials, it can likely be assumed that at least 25\% of them were HPV(+). Figure 1 shows the HPV(+) LTC higher by about 20\% compared with that representing the overall "altered" series. Therefore the real TG rate of altered RT for H\&N tumour sites other than OPC (HPV status was not counted during "altered" trials) might be even a quarter lower (about 1.5-2\%) than that estimated in the meta-analyses by Bourhis et al. [5].

During the last 20 years combined chemoradiation has become an attractive option of therapy offered to patients with locally advanced H\&N cancer. Results of many trials (15-20, 22) have approved the promising efficacy of this modality (tab. III), with 3-year LTC therapeutic gain in the range of $6->20 \%$ compared with RT alone. The highest TG has been reported when concurrent $\mathrm{CH}$-RT used three agents including taxane. A comparison of CH-RT with "altered RT" (fig. 2) shows that similar or even higher 3-year LTC of the advanced H\&N cancers after CH-RT was achieved using NTD doses lower than those applied in the "altered RT". Składowski [28] noted that for fairly homogeneous group of orohypopharyngeal and laryngeal cancer (T2-4N0-1) 2 cycles of CHT during RT produced much higher TG than one cycle, and the use of 3 cycles of $\mathrm{CHT}$ also improved the TG but not as substantially as 2 cycles.

\section{Other therapeutic options}

Progress in advanced RT technology has resulted in the development of precise static or dynamic 3D-IMRT, IGRT, V-MAT, proton therapy and stereotactic radiosurgery (which in fact is $4 \mathrm{D}$, - the fourth dimension is time). All these techniques and strategies are an important step forward in radiotherapy. The aim of radiotherapy has always been a major challenge: to deliver a higher dose to the tumour to improve LTC, in addition to a much lower dose beyond its margins to reduce treatment volume and to spare normal tissue (organs). Despite the many advantages, a risk of "dose cold spots" within the GTV cannot be ignored. If the planned total dose predicting high TCP is referred to $D_{95}$ within the GTV, but some GTV subvolume receives a slightly lower dose (cold spot) than real TCP lowers than predicted. Therefore Fowler et al. [24, 25] strongly advocated to use $D_{100}$ covering whole GTV in 3-, 4-D-RT plannings instead of $\mathrm{D}_{95}$, as recommended by the UICC [26].

The point which should be emphasized is that although all these high-tech 3,4-D-RT modalities are promising, not a single word has been presented concerning the lack of long-term results. According to Glatstein [8], trials objectively evaluating the IMRT have not yet been undertaken.

Protons therapy has been advised as an attractive challenger to photons, due to the higher RBE and specific dose distribution [26]. It is an extremely precise and combined method, but capital and realization costs are prohibitively high. Proton therapy planning faces many physical and biological traps.
Except for the base of the skull, and some types of brain and child specific tumours, no substantial advantage of protons over photons has been proved as yet. Therefore, important questions arise, such as, to what extent very high capital and operational costs justify clinically relevant therapeutic benefit of proton therapy? Despite many studies, including trials, there is still a "lack of evidence" in favour of protons over photon therapy, except for some specific tumour sites and types, mentioned earlier.

During the last decade stereotactic hyperfractionated radiosurgery (SHRS) has become an important and effective challenger to conventional and altered radiotherapy [27]. However, as usual in practice, there are some pros and cons of the SHRS. The pros are technological innovations of linear accelerators (CyberKnife) which generate a great number (even more than 100) of pencil beams focused on the tumour GTV boundary with a drop-down dose gradient beyond. SHRS can be termed like a "back to the future", which means, the use a single or a few large fraction doses (1 x 20-25 Gy, 3-4,5 x 5-10 Gy), that were used in the early years of radiotherapy but pretty quickly abandoned because of the severe, often lethal consequential late reactions in the normal tissues. After many decades, new technological developments have nowadays allowed us to return to this method using new tools. The SHRS is comfortable for patients since it lasts one or only a few days, and therefore, the negative part dose neutralized effect of tumour cell repopulation does not play a role. Furthermore, large doses modulate the immunological response, which effectively supports (radiation) cytotoxic effects. The SHRS produces high 80-95\% 2-3 year LTC with acceptable tolerance. However, the cons are that the use SHRS in practice is limited to very small (primary or metastatic) tumours.

The SHRS produces radical, curative but only local effect but not necessarily leading to permanent patient' cure. Thus, the number of candidates to the SHRS is limited. SHRS results in local control (at least 3-years) of small brain and extracranial lesions and is also highly effective in eradicating small, single or multiple metastatic lesions. Until now, SHRS has been used for head and neck cancers, to treat local recurrence after conventional RT producing about $60 \%$ of local control.

\section{Last minute!}

Nano-radioimmunotherapy (RIT) is advised as a promising new therapeutic strategy, and it has been tested in a few pilot clinical studies. Radiolabeled $\left({ }^{90} Y,{ }^{131} \mathrm{I}\right)$ monoclonal antibodies and radioimmunoliposomes loaded with a cytotoxic agent (i.e. ${ }^{99}$ Tc-anti-Iter2 Doxil) are delivered directly to tumour cell surface antigens where its radiolabeled and cytotoxic components are released into the tumour cells. The RIT pilot clinical efficacy is mainly tested for lymphomas and some solid tumours i.e. lung, colon, breast, prostate, kidney and ovary cancers.

Another new and promising field of interest is so-called FLASH radiation therapy which uses a very high pulsed dose 
rate of about 150-170 Gy/second. This method is in its experimental phase of animal and cell culture studies. It has already been established that FLASH increases radioresistance of various normal tissues by about 2-fold or more. Tumour effect (TCP) has not been established, yet. However, both concepts seem interesting and promising.

\section{Conclusions}

Reviewing the efficacy of various fractionated modalities used in daily practice leads to the conclusions that there is no a single privileged fractionation modality which produces highly beneficial results, at least 3-year LTC and OS, and therefore a single tolerance summit level also does not exist. It seems that the tolerance summit is only partly related to fractionation intensity, and in fact the summit for dose level depends on individual biological characteristics, radiosensitivity and irradiated volume of normal tissue(s) and the potential for repair capacity and immunological defense. Figure 4 summarizes the therapeutic gain of various dose fractionation regimens, and this shows that each regimen has its own summit. It raises upwards HPV(+) oropharyngeal cancer and SHRS therapy. On the other hand, Figure 3 shows that the rate of the TG strongly depends on so-called dose intensity - DI (TD/OTT), which expresses variations of four parameters, i.e. total dose, di, time intervals between daily fractions and the OTT. The larger the DI values the higher the TG benefit. Considering the various summits for different fractionation modalities, results are presented of many studies including trials that suggest that hyperfractionated radiotherapy combined with concurrent chemotherapy (with 3 agents including taxanes) is the most often used in daily practice to treat locally advanced head and neck cancer. The recent pilot study on erlotinib (anti EGFR) and bevacizumab (anty VEGFR) integrated with CH-RT (cispl) for locally advanced H\&N cancer resulted in 82\% LTC. We should probably continue to follow this path.
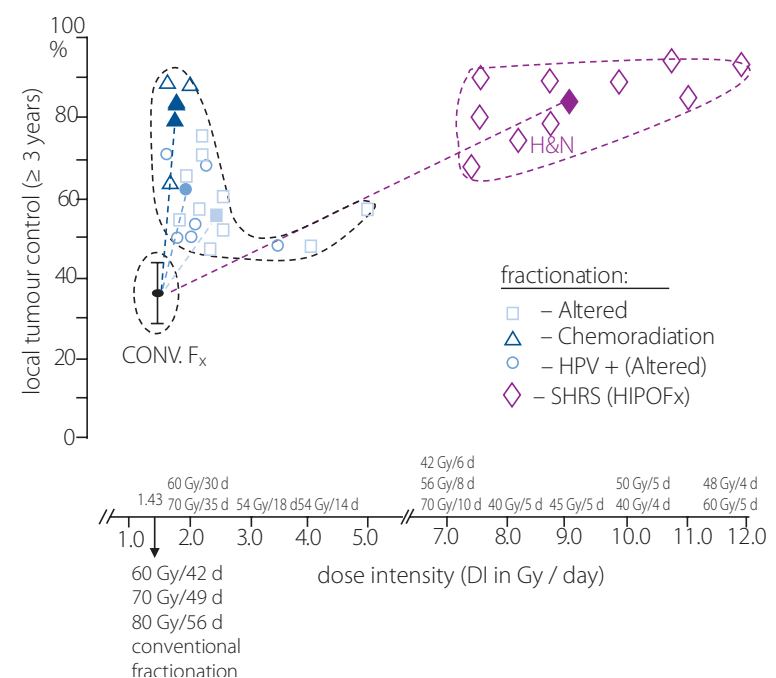

Figure 4. Local tumour control - dose intensity (DI) relationship for various dose fractionation regimens
Finally, should the average results of clinical trials often defined as "evidence based" be used as precise predictors for personalized radiotherapy for individual patients remain an open question? After all, the tolerance summit is not a single, universal dose level, but it is a variable characteristic for each individual patient.

\section{Conflict of interest: none declared}

\section{Bogusław Maciejewski}

Div. Research Programmes

M. Sklodowska-Curie National Research Institute of Oncology

Gliwice Branch

Wybrzeże Armii Krajowej 15

44-102 Gliwice, Poland

e-mail:boguslaw.maciejewski@io.gliwice.pl

Received: 27 Aug 2020

Accepted: 7 Sep 2020

\section{References}

1. Thames $\mathrm{H}$. On the origin of dose fractionation regimens in radiotherapy. Seminars in Radiation Oncology. 1992; 2(1): 3-9, doi: 10.1016/ s1053-4296(05)80043-8.

2. Suit H. The Gray Lecture 2001: coming technical advances in radiation oncology. Int J Radiat Oncol Biol Phys. 2002; 53(4): 798-809, doi: 10.1016/s0360-3016(02)02851-1, indexed in Pubmed: 12095545.

3. Dragun AE. Altered fractionation schedules. in Principles and Practice of Radiation Oncology. 7th ed. Wolter Kluwer, Philadelphia 2018: 308-328.

4. Ang KK. Altered fractionation schedules. In: Perez CA, Brady LW. ed. Principles and Practice of Radiation Oncology. Lippincot. Raven Publ 1998: 119-142.

5. Lacas B, Bourhis J, Overgaard J, et al. MARCH Collaborative Group, MARCH Collaborative Group, Meta-Analysis of Radiotherapy in Carcinomas of Head and neck (MARCH) Collaborative Group. Hyperfractionated or accelerated radiotherapy in head and neck cancer: a meta-analysis. Lancet. 2006; 368(9538): 843-854, doi: 10.1016/S0140-6736(06)691216, indexed in Pubmed: 16950362.

6. Lucas SB, Bourhis J, Overgaard J, et al. Role of radiotherapy fractionation in head and neck cancer (MARCH): an updated meta-analyses. Lancet Oncol. 2017; 18(9): 1-17, doi: 10.1016/S1470-2045(17)30458-8, indexed in Pubmed: 28757375.

7. Glatstein E. Personal thoughts on statistics, or lies, damn lies, and (oncologic) statistics. Int J Radiat Oncol Biol Phys. 2004; 58(5): 1329-1333, doi: 10.1016/j.jijobp.2003.11.034, indexed in Pubmed: 15050306.

8. Glatstein E. The return of the snake oil salesmen. Int J Radiat Onco Biol Phys. 2003; 55(3): 561-562, doi: 10.1016/s0360-3016(02)04204-9, indexed in Pubmed: 12573740.

9. Glatstein E. Black, White, or Shades of Gray? Int J Radiat Oncol Biol Phys. 2008; 72(5): 1307, doi: 10.1016/j.jijrobp.2008.09.001.

10. Saunders MI, Rojas AM, Parmar MKB, et al. CHART Trial Collaborators. Mature results of a randomized trial of accelerated hyperfractionated versus conventional radiotherapy in head-and-neck cancer. Int J Radiat Oncol Biol Phys. 2010; 77(1): 3-8, doi: 10.1016/j.ijrobp.2009.04.082, indexed in Pubmed: 20394851.

11. O'Sullivan B, Huang SH, Perez-Ordonez B, et al. Outcomes of HPV-related oropharyngeal cancer patients treated by radiotherapy alone using altered fractionation. Radiother Oncol. 2012; 103(1): 49-56, doi: 10.1016/j. radonc.2012.02.009, indexed in Pubmed: 22410204.

12. Huang SH, O'Sullivan B, Waldron J. The Current State of Biological and Clinical Implications of Human Papillomavirus-Related Oropharyngeal Cancer. Semin Radiat Oncol. 2018; 28(1): 17-26, doi: 10.1016/j.semradonc.2017.08.007, indexed in Pubmed: 29173751.

13. Maciejewski B, Składowski K. A review of combined treatment strategies for HPV(+), p16(+) oropharyngeal cancer - is de-escalated radiotherapy a convincing and promising paradigm? Nowotwory. Journal of Oncology. 2020; 70(6): 236-243, doi: 10.5603/njo.2020.0048.

14. Chera BS, Amdur RJ, Tepper J, et al. Phase 2 Trial of De-intensified Chemoradiation Therapy for Favorable-Risk Human Papillomavirus-Associated Oropharyngeal Squamous Cell Carcinoma. Int J Radiat 
Oncol Biol Phys. 2015; 93(5): 976-985, doi: 10.1016/j.jjrobp.2015.08.033, indexed in Pubmed: 26581135.

15. Brizel D. Radiotherapy and concurrent chemotherapy for the treatment of locally advanced head and neck squamous cell carcinoma. Semin Radiat Oncol. 1998; 8(4): 237-246, doi: 10.1016/s1053-4296(98)80021-0.

16. Bernier J, Bentzen SM. Altered fractionation and combined radio-chemotherapy approaches: pioneering new opportunities in head and neck oncology. Eur J Cancer. 2003; 39(5): 560-571, doi: 10.1016/ s0959-8049(02)00838-9, indexed in Pubmed: 12628834.

17. Bernier J. Current state-of-the-art for concurrent chemoradiation. Semin Radiat Oncol. 2009; 19(1): 3-10, doi: 10.1016/j.semradonc.2008.09.002, indexed in Pubmed: 19028339.

18. Denis F, Garaud P, Bardet E, et al. Final results of the 94-01 French Head and Neck Oncology and Radiotherapy Group randomized trial comparing radiotherapy alone with concomitant radiochemotherapy in advanced-stage oropharynx carcinoma. J Clin Oncol. 2004; 22(1): 69-76, doi: 10.1200/JCO.2004.08.021, indexed in Pubmed: 14657228.

19. Brizel DM, Vokes EE. Induction chemotherapy: to use or not to use? That is the question. Semin Radiat Oncol. 2009; 19(1): 11-16, doi: 10.1016/j. semradonc.2008.09.003, indexed in Pubmed: 19028340.

20. Pignon JP, Bourhis J, Domenge $C$, et al. Chemotherapy added to locoregional treatment for head and neck squamous-cell carcinoma: three meta-analyses of updated individual data. MACH-NC Collaborative
Group. Meta-Analysis of Chemotherapy on Head and Neck Cancer. Lancet. 2000; 355(9208): 949-955, indexed in Pubmed: 10768432.

21. Kaanders $\mathrm{JH}$, van der Kogel AJ, Ang KK. Altered fractionation: limited by mucosal reactions? Radiother Oncol. 1999; 50(3): 247-260, doi: 10.1016/ s0167-8140(99)00012-2, indexed in Pubmed: 10392810.

22. Blanchard P, Baujat B, Holostenco V. Meta-analysis of chemotherapy in head and neck cancer (MACH-NC): a comprehensive analysis by tumour site. Radiother Oncol. 2011; 100(1): 33-40, doi: 10.1016/j. radonc.2011.05.036, indexed in Pubmed: 21684027.

23. Glatstein E. The omega on alpha and beta. Int J Radiat Oncol Biol Phys. 2011; 81(2): 319-320, doi: 10.1016/j.jijrobp.2011.01.011, indexed in Pubmed: 21871342.

24. Fowler J, Chappell R, Ritter $M$. Is $\alpha / \beta$ for prostate tumors really low? Int J Radiat Oncol Biol Phys. 2001; 50(4): 1021-1031, doi: 10.1016/ s0360-3016(01)01607-8.

25. Fowler JF, Tomé WA, Fenwick JD, et al. A challenge to traditional radiation oncology. Int J Radiat Oncol Biol Phys. 2004; 60(4): 1241-1256, doi: 10.1016/j.jjrobp.2004.07.691, indexed in Pubmed: 15519797.

26. De La. Proton radiation therapy. Semin Radiat Oncol. 2018; 28: 75-160.

27. Maciejewski B, Suwiński R. Blamek S. Hipofrakcjonowana radiochirurgia stereotaktyczna. w. Radiobiologia kliniczna w radioonkologii. Medycyna Praktyczna. ; 2019: 99-103.

28. Składowski K. Personal communication. 